\title{
Assessment of safety and effectiveness of oral multiple sclerosis medication
}

Abdulrahman M. Al Turaiki, B. Pharm, Maha A. Al Ammari, Msc MPH,

Dalal A. Alabdulkarim, Msc Pharm, Abdullah U. Althemery, PhD.

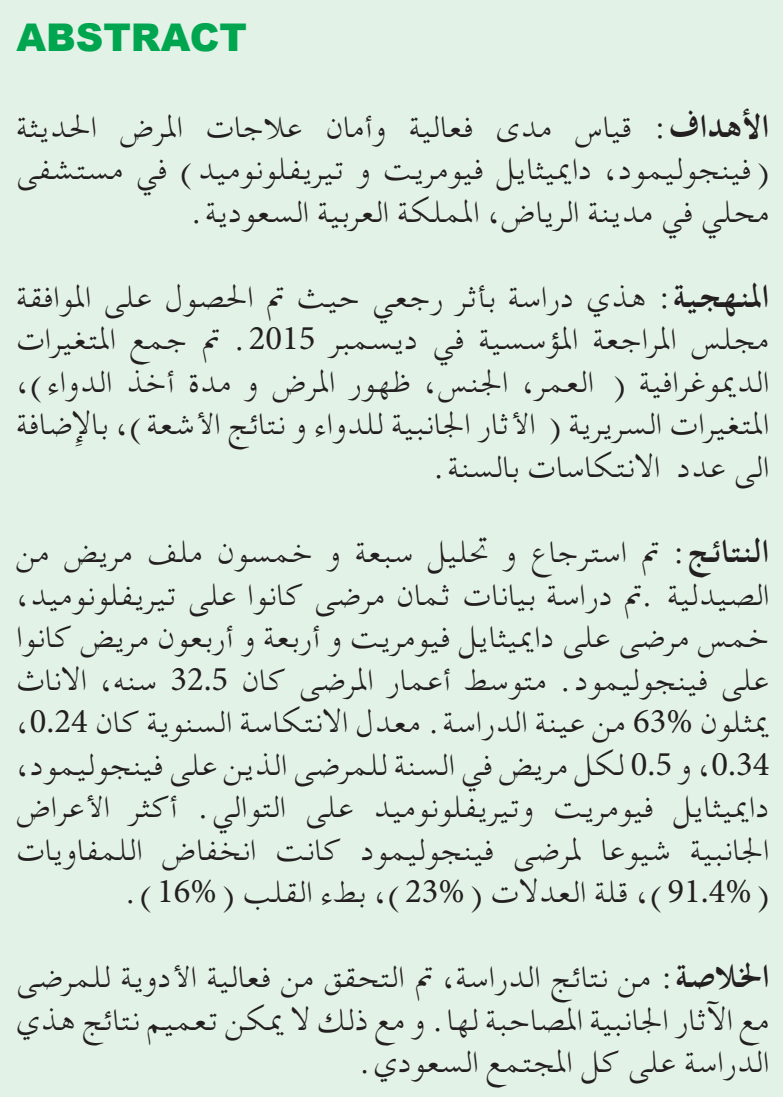

Objectives: To assess the effectiveness and safety profile of the new disease modifying drugs (fingolimod, teriflunomide, and dimethyl fumarate) at a local hospital in Riyadh, Saudi Arabia.

Methods: This is a retrospective cohort, where institutional review board approval was granted in December 2015. The study was conducted at King Abdulaziz Medical City Research Center, Riyadh, Saudi Arabia. Demographic variables (age, gender, disease onset, and duration on medication), clinical variables (medication side effects and radiological findings), in addition to relapse frequency per year was collected.

Results: Fifty-seven patients' records were retrieved from the pharmacy and included in the analysis. Eight patients were on teriflunomide, 5 patients on dimethyl fumarate and 44 patients on fingolimod were enrolled. The patients' average age was 32.5 years with female gender representing $63 \%$ the study population. Annual relapse rates were $0.24,0.34$, and 0.5 per patient per year for those taking fingolimod, dimethyl fumarate, and teriflunomide, correspondingly, lymphopenia (91.4\%), neutropenia $(23 \%)$, and bradycardia $(16 \%)$ were the most reported side effects for fingolimod therapy.

Conclusion: The study results were able to capture the effectiveness rate for the targeted treatment in the studied population, with the frequency of incidence of side effects. However, as these results cannot be generalized for the entire Saudi population.

\section{Saudi Med J 2019; Vol. 40 (11): 1116-1122} doi: $10.15537 /$ smj.2019.11.24630

From the Pharmaceutical Care Services, Ministry of the National GuardHealth Affairs (Al Turaiki, Al Ammari, Alabdulkarim), King Abdullah International Medical Research Center, and King Saud bin Abdulaziz University for Health Sciences, Riyadh; and from the Clinical Pharmacy Department (Althemery), College of Pharmacy, Prince Sattam bin Abdulaziz University, Al-Kharj, Kingdom of Saudi Arabia.

Received 29th July 2019. Accepted 9th October 2019.

Address correspondence and reprint request to: Dr. Abdullah Althemery, Assistant Professor, Department of Clinical Pharmacy, College of Pharmacy, Prince Sattam Bin Abdulaziz University, Al-Kharj, Kingdom of Saudi Arabia.E-mail: a.althemery@psau.edu.so

ORCID: https://orcid.org/0000-0002-3415-7685

$\mathrm{M}$ ultiple sclerosis (MS) is a chronic inflammatory autoimmune disease affecting the central nervous system (CNS) whose etiology is not clearly understood. ${ }^{1}$ Multiple sclerosis can be divided into 3 classes. ${ }^{2}$ The first class, relapsing-remitting MS (RRMS), is defined by a clear relapse followed by complete or a partial recovery, and it accounts for $85-90 \%$ of MS cases. ${ }^{3}$ The second type, primary progress MS (PPMS), is characterized by progressive disability without recovery and accounts for $10 \%$ of MS cases. ${ }^{4}$ The third type, secondary progressive 
MS (SPMS), can be identified by an initial relapse remission followed by continuous worsening without remission or minor improvement. ${ }^{2}$ It was estimated that over half of RRMS patients develop SPMS. ${ }^{5}$

In 2010, the U.S Food and Drug Administration (FDA) approved Fingolimod as the first oral therapy for managing RRMS. ${ }^{6}$ It acts by decreasing the ability of lymphocytes to emerge from the lymph node via activation of sphingosine-1 phosphate S1P receptor, leading to a decrease in the number of lymphocytes in the CNS and in disease activity. ${ }^{7}$ Fingolimod was studied in 3 large phase 3 trials. In the FREEDOMS and FREEDOMS II trials, it was compared using 2 doses, $0.5 \mathrm{mg}$ and $1.25 \mathrm{mg}$, versus a placebo, and in the TRANSFORMS trial, it was also compared using the same 2 doses but versus interferon beta-1a $30 \mu \mathrm{g}$ weekly. ${ }^{8,9}$

In September 2012, the FDA approved the second oral medication to treat RRMS, Teriflunomide. ${ }^{10}$ It reversibly obstructs pyrimidine synthesis by inhibiting dihydroorotate dehydrogenase enzymes in the mitochondria, ultimately leading to a decrease in the proliferation of $\mathrm{B}$ and $\mathrm{T}$ cells. ${ }^{11}$ Three large randomized trials were conducted on Teriflunomide involving 2 doses, $7 \mathrm{mg}$ or $14 \mathrm{mg}$, versus placebo in the TEMSO and TOWER trials, while the doses were set versus interferon beta-1a $44 \mu \mathrm{g} 3$ times weekly in the TENERE trial. ${ }^{12}$

The third medication, dimethyl fumarate (BG-12), was approved by the US FDA in March 2013. ${ }^{13}$ It has anti-inflammatory and cytoprotective properties via activation of the nuclear 1 factor (erythroid-derived2)like 2 (Nrf2) pathway. ${ }^{14}$ Dimethyl fumarate was studied in 2 phase 3 trials with $240 \mathrm{mg}$ either twice or 3 times daily versus placebo in the DEFINE and CONFIRM trials. ${ }^{14}$

Scant literature focuses on MS in the Kingdom of Saudi Arabia (KSA). ${ }^{15,16}$ An early work by Yaqub et al ${ }^{17}$ reported an increase incidence of MS in the Kingdom. In 2015, the Saudi Arabian National Multiple Sclerosis Registry (NMSR) was initiated with the goal of exploring the epidemiology and clinical symptoms of MS in the KSA. ${ }^{15}$ The prevalence of MS among Saudis is an estimated 40 cases per 100,000, which is considered low compared with other parts of the world (namely, more than 100/100,000 in Europe). ${ }^{17,18}$ Saudi females

Disclosure. Authors have no conflict of interests, and the work was not supported or funded by any drug company. have a higher prevalence of MS compared to males (2:1 ratio). ${ }^{15}$

A study focusing on treating MS in KSA is needed, as most of the previous literature explored the epidemiological view of MS. The main and first objective of this study involved assessing the effectiveness and safety profile of the new disease modifying drugs (fingolimod, teriflunomide, and dimethyl fumarate) at a local hospital in Riyadh, KSA. The second objective sought to explore the monitoring frequency for each medication and their discontinuation rate. The third objective aimed at evaluating the previous treatment before the new disease modifying drugs and the reasons for their discontinuation.

Methods. A retrospective cohort design was applied to explore the effectiveness and safety profile of fingolimod, teriflunomide, and dimethyl fumarate for patients with RRMS. The data collection started in 2016. International Review Board approval from the King Abdullah International Medical Research Center (KAIMRC) was received in December 2015. The study was conducted at King Abdulaziz Medical City-CR (KAMC-CR), which is a tertiary hospital in Riyadh, Saudi Arabia. Fingolimod, teriflunomide, and dimethyl fumarate are available based on patients and physician preferences.

The first objective involved assessing the effectiveness and safety profile of the latest MS modifying drugs. The drugs include fingolimod, teriflunomide, and dimethyl fumarate. The study sample retrieved from the pharmacy computer system and reviewed retrospectively. All patients who received at least one dose of the targeted therapy according to the pharmacy records were reviewed for eligibility. The inclusion criteria were the diagnosis of RRMS and the presence of at least one dose of fingolimod, teriflunomide, or dimethyl fumarate. The exclusion criteria were incomplete medical records (patients came for a second opinion or did not followup).

Effectiveness was measured through relapse rate per year and magnetic resonance imaging (MRI) results. Results from the MRI include new gadolinium enhancinglesions, new T2 weighted lesions, and enlarged T2 weighted lesions. Safety profile was measured through the presence of side effects. Each medication associated with different side effects was reported by various randomized clinical trials or metaanalyses. For fingolimod, the side effects comprise bradycardia (less than 65 beats per minute), hepatotoxicity (alanine 
transaminase greater than upper limit of normal), lymphopenia (less than $1^{*} 109$ per liter), neutropenia (absolute neutrophil count less than $2 * 109$ per liter), and infections (mainly herpes and upper respiratory tract infection). ${ }^{19-21}$ For Teriflunomide, the side effects include hair thinning, headache, diarrhea, peripheral neuropathy, high systolic blood pressure (more than $160 \mathrm{~mm} \mathrm{Hg}$ ), and neutropenia. ${ }^{22-24}$ The side effects for dimethyl fumarate consist of proteinuria, pruritus, gastrointestinal symptoms, flushes, and infections., ${ }^{3,25-27}$ The second objective was exploring the frequency of monitoring for each medication, mainly hepatic and blood pressure monitoring and their discontinuation rate. Discontinuation was defined as stopping treatment for any reason.

The third objective covered the previous treatments before the new disease-modifying drugs and the reasons behind their discontinuation. These treatments include interferon beta-1a (subcutaneous SC or intramuscular IM), interferon beta- $1 \mathrm{~b}$ and natalizumab. The reasons for discontinuation were classified into 5 categories: medication intolerance, failure of treatment, side effect, presence of anti-JC-virus (JCV) antibodies associated with natalizumab therapy, and unknown reason.

In addition to the aforementioned variables, age, gender, onset of MS, and duration of therapy were also collected. All the clinical data and variables were collected from either the patient file or the hospital information system and compiled in the data collection sheet. Descriptive data were also conducted, including percentages. Depending of the assumptions, Chi-squared test or Fisher's exact test of independence were employed to explore the relationship between different categories in the dependent variable (type of treatment) and other categorical independent variables. All data analyses were conducted using R:A Language and Environment for Statistical Computing.

Results. Fifty-nine patients' records were retrieved from the pharmacy and reviewed for eligibility. Two patients on fingolimod were excluded because they had been diagnosed with SPMS; the remaining 57 patients were included (44 on fingolimod, 8 on teriflunomide, and 5 on dimethyl fumarate).

Tables $1 \& 2$ list the current treatments used, giving their averages and frequencies. The cohort's average age was 32.5 years $( \pm 2.31)$. On average, therapy lasted longest for patients treated with fingolimod (16.59 months) but was shortest for those treated with dimethyl fumarate (7 months). Patients treated with teriflunomide had the longest onset of MS (6.9 years versus the cohort average of 6.2 years). Annual relapse rates were $0.24,0.34$, and 0.5 per patient per year for those taking fingolimod, dimethyl fumarate, and teriflunomide.

Females represented $63 \%$ of the study population, and that aligned with each treatment group. More than $70 \%$ of the members of each treatment group did not report relapses. Among patients who underwent MRI after starting the therapy, $14.3 \%$ of the fingolimod, $50 \%$ of the dimethyl fumarate, and $16 \%$ of the teriflunomide treatment groups, showed new gadolinium-enhancing lesions. New T2-weighted lesions were seen in 19\% of patients on fingolimod as well as in $50 \%$ of patients on dimethyl fumarate or teriflunomide. Enlarged T2-weighted lesions were seen in $9.5 \%$ of patients on fingolimod and in $33.3 \%$ of patients on teriflunomide; no lesions were seen in patients on dimethyl fumarate.

The most frequently reported side effects associated with use of fingolimod were lymphopenia (91.4\%), neutropenia (23\%), and bradycardia (16\%). Of patients who used teriflunomide, $12.5 \%$ reported hair thinning, headache, diarrhea, high systolic blood pressure, peripheral neuropathy, and neutropenia. No side effects were documented for patients who used dimethyl fumarate (Table 3). No malignancies were reported in association with any of the treatments used by this cohort of patients.

Table 4 \& Table 5 describe previous treatments used as well as the reasons those treatments failed. More than half of patients had taken Interferon Beta-1a, whether subcutaneously $(36 \%)$ or intramuscularly $(21 \%)$. A

Table 1 - Description of current treatment (means).

\begin{tabular}{lcccc}
\hline Factor & Fingolimod & Treatments & \multicolumn{2}{c}{ Total } \\
& Dimethyl fumarate & Teriflunomide & \\
\hline Age (years) & $31.64(29.17-34.09)$ & $29.80(20.39-39.23)$ & $39.37(30.87-47.87)$ & $32.56(30.25-34.86)$ \\
Duration of therapy (months) & $16.59(13.38-19.79)$ & $7.00(0.25-13.74)$ & $12.00(6.96-17.03)$ & $15.10(12.43-17.77)$ \\
$\begin{array}{l}\text { Onset of MS (years) } \\
\text { Annual relapse rate (rate/ }\end{array}$ & $6.14(4.98-7.30)$ & $5.70(0.47-11.87)$ & $6.98(3.33-10.64)$ & $\mathbf{6 . 2 2}(5.17-7.26)$ \\
patient/year) & 0.24 & 0.34 & 0.50 & $\mathbf{0 . 2 8}$ \\
\hline
\end{tabular}


Table 2 - Description of current treatment (frequencies).

\begin{tabular}{|c|c|c|c|c|c|}
\hline \multirow[t]{2}{*}{ Factors } & \multicolumn{3}{|c|}{ Treatments } & \multirow[t]{2}{*}{ Total } & \multirow[t]{2}{*}{$P$-value } \\
\hline & Fingolimod & $\begin{array}{l}\text { Dimethyl } \\
\text { Fumarate }\end{array}$ & Teriflunomide & & \\
\hline \multicolumn{6}{|l|}{ Gender } \\
\hline Male & $17(29.8)$ & $1(1.8)$ & $3(5.3)$ & $21(36.8)$ & 0.89 \\
\hline Female & $27(47.4)$ & $4(7.0)$ & $5(8.8)$ & $36(63.2)$ & \\
\hline \multicolumn{6}{|c|}{ Reported side effects* } \\
\hline No & $10(17.5)$ & $5(8.8)$ & $3(5.3)$ & $18(31.6)$ & 0.001 \\
\hline Yes & $34(59.7)$ & $0(0.0)$ & $5(8.8)$ & $39(68.4)$ & \\
\hline \multicolumn{6}{|c|}{ Reported relapse } \\
\hline No & $31(54.4)$ & $4(7.0)$ & $5(8.8)$ & $40(70.2)$ & 0.88 \\
\hline Yes & $13(22.8)$ & $1(1.8)$ & $3(5.26)$ & $17(29.8)$ & \\
\hline \multicolumn{6}{|c|}{ MRI monitoring } \\
\hline No & $23(40.4)$ & $3(5.3)$ & $2(3.5)$ & $28(49.1)$ & 0.38 \\
\hline Yes & $21(36.8)$ & $2(3.5)$ & $6(10.5)$ & $29(50.9)$ & \\
\hline \multicolumn{6}{|c|}{ New gadolinium enhancing lesion ${ }^{\dagger}$} \\
\hline No & $18(31.6)$ & $1(1.8)$ & $5(8.8)$ & $24(42.1)$ & 0.28 \\
\hline Yes & $3(5.3)$ & $1(1.8)$ & $1(1.8)$ & $5(8.8)$ & \\
\hline \multicolumn{6}{|c|}{ New T2 weighted lesion } \\
\hline No & $17(29.8)$ & $1(1.8)$ & $3(5.3)$ & $21(36.8)$ & 0.19 \\
\hline Yes & $4(7.0)$ & $1(1.8)$ & $3(5.3)$ & $8(14.0)$ & \\
\hline \multicolumn{6}{|c|}{ Enlarged T2 weighted lesion } \\
\hline No & $19(33.3)$ & $2(3.5)$ & $4(7.0)$ & $25(43.9)$ & 0.24 \\
\hline Yes & $2(3.5)$ & $0(0.0)$ & $2(3.5)$ & $4(7.0)$ & \\
\hline \multicolumn{6}{|c|}{ Treatment discontinuation } \\
\hline No & $42(73.7)$ & $5(8.8)$ & $6(10.5)$ & $53(93.0)$ & 0.12 \\
\hline Yes & $2(3.5)$ & $0(0.00)$ & $2(3.5)$ & $4 \quad(7.0)$ & \\
\hline
\end{tabular}

Table 3 - Side effect explored in each current treatment.

\begin{tabular}{lr}
\hline Detected side effect & $\begin{array}{c}\text { Number of patients } \\
(\%)\end{array}$ \\
\hline Fingolimod & $32(91.0)$ \\
Lymphopenia & $8(23.0)$ \\
Neutropenia & $7(16.0)$ \\
Bradycardia & $6(13.0)$ \\
Infection & $2(5.6)$ \\
Hepatotoxicity & \\
Dimethyl Fumarate & 0 \\
Proteinuria & 0 \\
Gastrointestinal & 0 \\
Flushes & 0 \\
Pruitus & 0 \\
Infection & \\
Teriflunomide & $1(12.5)$ \\
Hair thinning & $1(12.5)$ \\
Headache & $1(12.5)$ \\
Diarrhea & $1(12.5)$ \\
Neutropenia & $1(12.5)$ \\
High systolic blood pressure & 0 \\
Infection & 0 \\
\hline Hepatotoxicity & \\
\hline &
\end{tabular}

third of patients reported that previous treatments had failed, and $28 \%$ of patients who had changed their mode of treatment because of an inability to tolerate previous treatments. A total of 4 patients had discontinued their medications after contracting an infection; 3 of them had been treated using fingolimod.

Discussion. This study included 57 patients who had been diagnosed with RRMS. This sample size was similar to those of previous studies focusing on treatment of multiple sclerosis (MS), whether in Saudi Arabia or internationally. ${ }^{28,29}$ Algahtani et $\mathrm{al}^{28}$ conducted a cross-sectional study in Jeddah, Saudi Arabia, in which they evaluated various treatments for RRMS among a sample size of 32 patients. In Switzerland, Naegelin et $\mathrm{al}^{29}$ evaluated different types of MS therapy among 25 patients. These relatively small sample sizes can be attributed to 2 factors: the studies' having focused on a single site rather than multiple sites and MS's remaining a low prevalence disease. ${ }^{30}$

The effectiveness and safety profiles of fingolimod, teriflunomide, and dimethyl fumarate was assessed. 
Table 4 - Previous Treatment.

\begin{tabular}{|c|c|c|c|c|c|}
\hline \multirow[t]{2}{*}{ Factor } & \multicolumn{3}{|c|}{ Treatments } & \multirow[t]{2}{*}{ Total } & \multirow[t]{2}{*}{$P$-value } \\
\hline & Fingolimod & $\begin{array}{l}\text { Dimethyl } \\
\text { Fumarate }\end{array}$ & Teriflunomide & & \\
\hline \multicolumn{6}{|c|}{ Utilized treatment } \\
\hline No & $7(12.3)$ & $2(3.5)$ & $1 \quad(1.8)$ & $10(17.5)$ & 0.38 \\
\hline Yes & $37(64.9)$ & $3(5.3)$ & $7(12.3)$ & $47(82.5)$ & \\
\hline \multicolumn{6}{|c|}{ Interferon beta-1a subcutaneously } \\
\hline No & $28(49.1)$ & $3(5.3)$ & $5(8.8)$ & $36(63.2)$ & 0.99 \\
\hline Yes & $16(28.1)$ & $2(3.5)$ & $3(5.3)$ & $21(36.8)$ & \\
\hline \multicolumn{6}{|c|}{ Interferon beta-1a intramuscular } \\
\hline No & $34(59.7)$ & $5(8.8)$ & $6(10.5)$ & $45(79.0)$ & 0.71 \\
\hline Yes & $10(17.5)$ & 0 & $2(3.5)$ & $12(21.1)$ & \\
\hline \multicolumn{6}{|c|}{ Interferon beta-1b subcutaneously } \\
\hline No & $40(70.2)$ & $5(8.8)$ & $8(14.0)$ & $53(93.0)$ & 0.99 \\
\hline Yes & $4 \quad(7.0)$ & 0 & 0 & $4 \quad(7.0)$ & \\
\hline \multicolumn{6}{|c|}{ Natalizumab intraveous } \\
\hline No & $40(70.2)$ & $5(8.8)$ & $7(12.3)$ & $52(91.2)$ & 0.99 \\
\hline Yes & $4 \quad(7.0)$ & 0 & 1 (1.8) & $5(8.8)$ & \\
\hline \multicolumn{6}{|c|}{ Mycophenolate per os } \\
\hline No & $43(75.4)$ & $5(8.8)$ & $8(14.0)$ & $56(98.3)$ & 0.99 \\
\hline Yes & $1 \quad(1.8)$ & 0 & 0 & $1 \quad(1.8)$ & \\
\hline \multicolumn{6}{|c|}{ Teriflunomide per os } \\
\hline No & $42(73.7)$ & $5(8.8)$ & $7(12.3)$ & $55(96.5)$ & 0.99 \\
\hline Yes & $2(3.5)$ & 0 & 0 & $2(3.5)$ & \\
\hline \multicolumn{6}{|c|}{ Fingolimod per os } \\
\hline No & $44(77.2)$ & $4(7.0)$ & $7(12.3)$ & $55(96.5)$ & 0.99 \\
\hline Yes & 0 & $1(1.8)$ & $1 \quad(1.8)$ & $2(3.5)$ & \\
\hline
\end{tabular}

Table 5 - Treatment history and the reason of treatment changed.

\begin{tabular}{|c|c|c|c|c|c|}
\hline \multirow[t]{2}{*}{ Factor } & \multicolumn{3}{|c|}{ Treatments } & \multirow[t]{2}{*}{ Total } & \multirow[t]{2}{*}{$P$-value } \\
\hline & Fingolimod & $\begin{array}{l}\text { Dimethyl } \\
\text { Fumarate }\end{array}$ & Teriflunomide & & \\
\hline \multicolumn{6}{|c|}{ Treatment failure } \\
\hline No & $26(45.6)$ & $5(8.8)$ & $7(12.3)$ & $38(66.7)$ & 0.10 \\
\hline Yes & $18(31.2)$ & 0 & $1(1.8)$ & $19(33.3)$ & \\
\hline \multicolumn{6}{|c|}{ Intolerant } \\
\hline No & $33(57.9)$ & $3(5.3)$ & $5(8.8)$ & $41(71.9)$ & 0.59 \\
\hline Yes & $11(19.3)$ & $2(3.5)$ & $3(5.3)$ & $16(28.1)$ & \\
\hline \multicolumn{6}{|c|}{ Side effect } \\
\hline No & $43(75.4)$ & $4(7.0)$ & $7(12.3)$ & $54(94.7)$ & 0.12 \\
\hline Yes & $1(1.8)$ & $1(1.8)$ & $1(1.8)$ & $3(5.3)$ & \\
\hline \multicolumn{6}{|c|}{ John Cunningham virus antibodies positive* } \\
\hline No & $41(71.9)$ & $5(8.8)$ & $7(12.3)$ & $53(93.0)$ & 0.65 \\
\hline Yes & $3(5.3)$ & 0 & $1(1.8)$ & $4(7.0)$ & \\
\hline \multicolumn{6}{|c|}{ Unknown reason } \\
\hline No & $40(70.2)$ & $5(8.8)$ & $7(12.3)$ & $41(71.9)$ & 0.99 \\
\hline Yes & $4(7.1)$ & 0 & $1(1.8)$ & $5(8.8)$ & \\
\hline
\end{tabular}


The effectiveness was captured by tracking relapse rate per year and by assessing MRI results. Relapse rate per patient per year varied: 0.5 for teriflunomide, 0.34 for dimethyl fumarate, and 0.24 for fingolimod. This study's estimate for fingolimod aligned with the estimates reported by previous clinical trials, such as the TRANSFORMS trial (0.2), FREEDOMS trial (0.18), and FREEDOMS II trial (0.21). ${ }^{8,9}$ The relapse rate recorded for dimethyl fumarate, however, was higher than seen in previous clinical trials, such as the DEFINE trial (0.17) and CONFIRM trial $(0.22),{ }^{14}$ as was the rate for teriflunomide compared with the figures seen in the TEMSO trial (0.37), TOWER trial (0.32), and TENERE trial (0.26). ${ }^{12}$ Notably, however, the fingolimod group was the largest in this study, perhaps explaining why the estimates for this group more closely aligned with the findings of clinical trials than were the estimates for the 2 other groups.

Effectiveness can also be measured using MRI results, in this case, in descending order of frequency, new T2-weighted lesion, new gadolinium-enhancing lesion, and enlarged T2-weighted lesion. However, these MRI results should be interpreted with caution, as only half of patients underwent MRI monitoring, an alarming finding considering that the International Advisory Committee on Clinical Trials of MS has recommended that MRI scanning be conducted at least annually. ${ }^{2}$ Despite this recommendation, however, MRI frequency, timing, and protocols differ among care centers, both locally and internationally. ${ }^{31}$

The discontinuation rate was explored, which at $7.2 \%$ overall was significantly lower than the $29.7 \%$ reported by Hua et al. ${ }^{32}$ The magnitude of this difference might be a function of the average age of study participants, 32 years for the present study versus 60 years for the prior one. ${ }^{32}$ Moreover, the treatments included in our study were given as many patients' second-line therapy, whereas previous reports focused on discontinuation rates for first-line therapies. ${ }^{33}$ In our study population, the fingolimod group reported a $4.5 \%$ discontinuation rate, lower than that seen in larger clinical trials, such as the TRANSFORMS trial (5.6\%), FREEDOMS trial (7.5\%), and FREEDOMS II trial (18\%).8,9 In the teriflunomide group, 2 patients $(25 \%)$ discontinued the medication, compared with $10.9 \%$ in the TEMSO trial, $16 \%$ in the TOWER trial, and $10.9 \%$ in the TENERE trial. ${ }^{12}$

Finally, treatment history was investigated. More than $80 \%$ of the study sample had used previous treatments, half of which had in turn involved use of Interferon Beta-1a. These results align with international therapeutic practice, for although no clear guidelines exist for the pharmacological management of MS, many clinicians consider Interferon Beta-1a to be the first-line therapy for RRMS.${ }^{34}$ However, more than a third of our population had changed their first-line therapy after it had failed, consistent with previous reports in the literature that treatment failure is a significant burden on patients who have MS. ${ }^{35,36}$ However, as definitions and timings of treatment failure are inconsistent internationally, further research is needed into this issue. $^{36}$

Study limitations. The average duration of treatment in this study was 15 months. However, even though longer durations are preferred, the study was nonetheless able to capture significant number of relapse rates for each treatment group. Moreover, a 15-months duration of treatment aligns with the ranges seen in larger clinical trials that have studied treatment for MS, which have featured durations ranging from 12 months to 24 months. ${ }^{8,9,12,14}$ Additionally, the main parameters used to gauge effectiveness in this study were relapse rate per year and MRI results; a proposed targeted MS treatment endpoint that relied on evidence of disease activity status was discussed in the literature but could not be measured in this study. ${ }^{37}$ Further research, however, could apply this new measure to compare various MS treatments.

In conclusion, our results were able to capture the effectiveness rate for the targeted treatment in the studied population, with the frequency of incidence of side effects. However, as these results cannot be generalized for the entire Saudi population, owing to this study's small sample size, clinicians should focus on monitoring patients for both effectiveness and safety.

Acknowledgment. We would like to show our gratitude to Faisal Al Harbi, registered pharmacist at the Ministry of the National Guard, Riyadh, Saudi Arabia, for his assistance during the data collection process of this study.

\section{References}

1. Lemus HN, Warrington AE, Rodriguez M. Multiple sclerosis: Mechanisms of disease and strategies for myelin and axonal repair. Neurol Clin 2018; 36: 1-11.

2. Lublin FD, Reingold SC, Cohen JA, Cutter GR, Sørensen PS, Thompson AJ, et al. Defining the clinical course of multiple sclerosis: the 2013 revisions. Neurology 2014; 83: 278-286.

3. Soini E, Joutseno J, Sumelahti M-L. Cost-utility of First-line Disease-modifying Treatments for Relapsing-Remitting Multiple Sclerosis. Clin Ther 2017; 39: 537-557.e10.

4. Ontaneda D, Fox RJ. Progressive multiple sclerosis. Curr Opin Neurol 2015; 28: 237.

5. Dutta R, Trapp BD. Relapsing and progressive forms of multiple sclerosis: insights from pathology. Curr Opin Neurol 2014; 27 : 271-278. 
6. FDA. Fingolimod (marketed as Gilenya) Information [cited 2018]. Available from: https://www.fda.gov/Drugs/DrugSafety/ ucm626095.htm

7. Castro-Borrero W, Graves D, Frohman TC, Flores AB, Hardeman P, Logan D, et al. Current and emerging therapies in multiple sclerosis: a systematic review. Ther Adv Neurol Disord 2012; 5: 205-220.

8. Khatri BO. Fingolimod in the treatment of relapsing-remitting multiple sclerosis: long-term experience and an update on the clinical evidence. Ther Adv Neurol Disord 2016; 9: 130-147.

9. Calabresi PA, Radue E-W, Goodin D, Jeffery D, Rammohan KW, Reder AT, et al. Safety and efficacy of fingolimod in patients with relapsing-remitting multiple sclerosis (FREEDOMS II): a double-blind, randomised, placebo-controlled, phase 3 trial. Lancet Neurol 2014; 13: 545-556.

10. Department of Health and Human Services. NDA 202992 [cited 2012]. Available from: https://www.accessdata.fda.gov/ drugsatfda_docs/appletter/2012/202992orig1s000ltr.pdf

11. Kieseier BC, Wiendl H. New evidence for teriflunomide in multiple sclerosis. Lancet Neurol 2014; 13: 234-235.

12. Guarnera C, Bramanti P, Mazzon E. Comparison of efficacy and safety of oral agents for the treatment of relapsing-remitting multiple sclerosis. Drug Des Devel Ther 2017; 11: 2193-2207.

13. Department of Health and Human Services. NDA 204063/S-10 [cited 2014]. Available from: https://www.accessdata.fda.gov/ drugsatfda_docs/nda/2014/204063Orig1s010.pdf

14. Bomprezzi R. Dimethyl fumarate in the treatment of relapsingremitting multiple sclerosis: an overview. Ther Adv Neurol Disord 2015; 8: 20-30.

15. Al-Jumah M, Bunyan R, Al Otaibi H, Cupler E, Ishak S, Shami S, et al. The Saudi Arabian National Multiple Sclerosis Registry (NMSR): Initial Results Saudi MS Registry Study Group* (P2.390). Neurology 2018; 90 (15 Supplement): P2.390.

16. Yaqub BA, Daif AK. Multiple sclerosis in Saudi Arabia. Neurology 1988; 38: 621-623.

17. Bohlega S, Inshasi J, Al Tahan AR, Madani AB, Qahtani H, Rieckmann P. Multiple sclerosis in the Arabian Gulf countries: a consensus statement. J Neurol 2013; 260: 2959-2963.

18. Kingwell E, Marriott JJ, Jetté N, Pringsheim T, Makhani N, Morrow SA, et al. Incidence and prevalence of multiple sclerosis in Europe: a systematic review. BMC Neurol 2013; 13: 128.

19. Yoshii F, Moriya Y, Ohnuki T, Ryo M, Takahashi W. Neurological safety of fingolimod: An updated review. Clin Exp Neuroimmunol 2017; 8: 233-2343.

20. Tanaka M, Park K, Tanaka K. Reduced fingolimod dosage treatment for patients with multiple sclerosis and lymphopenia or neutropenia. Mult Scler 2013; 19: 1244-1245.

21. Ayzenberg I, Hoepner R, Kleiter I. Fingolimod for multiple sclerosis and emerging indications: appropriate patient selection, safety precautions, and special considerations. Ther Clin Risk Manag 2016; 12: 261-272.

22. He D, Zhang C, Zhao X, Zhang Y, Dai Q, Li Y, et al. Teriflunomide for multiple sclerosis. Cochrane Database Syst Rev 2016; 22: CD009882.

23. Canadian Agency for Drugs and Technologies in Health. Teriflunomide (Aubagio) (14 mg Film-coated Tablet): Teriflunomide is indicated as monotherapy for the treatment of patients with relapsing-remitting multiple sclerosis to reduce the frequency of clinical exacerbations and to delay the accumulation of Phys. CADTH Common Drug Rev 2014;
24. Miller AE. Teriflunomide: a once-daily oral medication for the treatment of relapsing forms of multiple sclerosis. Clin Ther 2015; 37: 2366-23680.

25. Fox EJ, Vasquez A, Grainger W, Ma TS, von Hehn C, Walsh J, et al. Gastrointestinal Tolerability of Delayed-Release Dimethyl Fumarate in a Multicenter, Open-Label Study of Patients with Relapsing Forms of Multiple Sclerosis (MANAGE). Int J MS Care 2016; 18: 9-18.

26. Xu Z, Zhang F, Sun F, Gu K, Dong S, He D. Dimethyl fumarate for multiple sclerosis. Cochrane Database Syst Rev 2015; (4): CD011076.

27. Ochi H, Niino M, Onizuka Y, Hiramatsu K, Hase M, Yun J, et al. 72-week safety and tolerability of dimethyl fumarate in japanese patients with relapsing-remitting multiple sclerosis: Analysis of the randomised, double blind, placebo-controlled, phase III APEX study and its open-label extension. Adv Ther 2018; 35: 1598-1611.

28. Algahtani H, Shirah B, Abobaker H, Alghanaim N, Kamel F. Natalizumab Treatment for Relapsing-Remitting Multiple Sclerosis: The Experience From Saudi Arabia. Clin Neuropharmacol 2018; 41: 199-201.

29. Naegelin Y, Rasenack M, Andelova M, Von Felten S, FischerBarnicol B, Amann M, et al. Shortening the washout to 4 weeks when switching from natalizumab to fingolimod and risk of disease reactivation in multiple sclerosis. Mult Scler Relat Disord 2018; 25: 14-20.

30. Yamout B, Alroughani R, Al-Jumah M, Goueider R, Dahdaleh $\mathrm{M}$, Inshasi $\mathrm{J}$, et al. Consensus recommendations for the diagnosis and treatment of multiple sclerosis: the Middle East North Africa Committee for Treatment and Research In Multiple Sclerosis (MENACTRIMS). Curr Med Res Opin 2015; 31: 1349-1361.

31. Vågberg M, Axelsson M, Birgander R, Burman J, Cananau C, Forslin Y, et al. Guidelines for the use of magnetic resonance imaging in diagnosing and monitoring the treatment of multiple sclerosis: recommendations of the Swedish Multiple Sclerosis Association and the Swedish Neuroradiological Society. Acta Neurol Scand 2017; 135: 17-24.

32. Hua LH, Fan TH, Conway D, Thompson N, Kinzy TG. Discontinuation of disease-modifying therapy in patients with multiple sclerosis over age 60. Mult Scler 2019; 25: 699-708.

33. Olek MJ, Mowry E. Disease-modifying treatment of relapsingremitting multiple sclerosis in adults. [cited 2019 Sep]. Available from: https://www.uptodate.com/contents/disease-modifyingtreatment-of-relapsing-remitting-multiple-sclerosis-in-adults

34. La Mantia L, Vacchi L, Di Pietrantonj C, Ebers G, Rovaris M, Fredrikson $S$, et al. Interferon beta for secondary progressive multiple sclerosis. Cochrane Database Syst Rev 2012; 18 : CD005181.

35. Pfeuffer S, Ruck T, Kleinschnitz C, Wiendl H, Meuth SG. Failed, interrupted and inconclusive trials on relapsing multiple sclerosis treatment: update 2010-2015. Expert Rev Neurother 2016; 16: 689-700.

36. Cristiano E, Alonso R, Alvez Pinheiro A, Bacile EA, Balbuena $\mathrm{ME}$, Ballario $\mathrm{C}$, et al. Argentinean recommendations on the identification of treatment failure in relapsing remitting multiple sclerosis patients. J Neurol Sci 2018; 385: 217-224.

37. Rotstein DL, Healy BC, Malik MT, Chitnis T, Weiner HL. Evaluation of no evidence of disease activity in a 7-year longitudinal multiple sclerosis cohort. JAMA Neurol 2015; 72: 152-158. 